of Experimental Psychology, 1969, 81, 360-364.

NOTE

1. This research was supported in part by Research Grant 2634 from the University of
California, Los Angeles. Appreciation is expressed to Evelyn Proctor and Margaret Sacks for their help in this study, and to the University Elementary School at UCLA for their cooperation in providing Ss for the research.

\title{
On predicting constrained associates from long-term memory
}

\author{
ELIZABETH F. LOFTUS, Stanford \\ University, Stanford, Calif. 94305, and \\ JONATHAN L. FREEDMAN, Columbia \\ University, New York, N.Y. 10027
}

Forty $S$ s gave constrained associates to a conceptual category plus an alphabetic letter (e.g., a musical instrument beginning with " $V$ "). The probability of occurrence of each correct response was predicted from Luce's choice axiom on the basis of associative norms collected by Battig \& Montague (1969). For example, the predicted probability of "violin" being given to "musical instrument starting with $V$ " was calculated as the proportion in the norms of "violin" responses to all responses starting with " $V$ " to the category "musical instrument." The correlation of the predicted and empirical proportions was. 91 .

The purpose of this note is to show the applicability of Luce's choice axiom (Luce, 1959) to data obtained in a constrained association task. The task will be described first, then Luce's axiom, then the data testing the axiom.

College Ss were asked to give verbal associations that met two constraints. For the data of interest the constraints were that the associate had to belong to a specified conceptual category and the word had to begin with a specified letter. For example, the constraints might be "name of a musical instrument beginning with "V" and acceptable responses would be "violin" and "viola." Although the original purpose of this experiment concerned response latencies as a function of various characteristics of the constraints, the present report concerns the relative frequencies of the constrained associates and their prediction by Luce's axiom.

Some notation is needed for stating Luce's axiom. Let $\mathrm{C}$ denote the set of all responses in a particular category (e.g., musical instruments) and let $R$ denote a subset of $C$ that includes a particular response, $x$. $R$ could be the set of all responses in $\mathrm{C}$ that begin with a particular letter and $x$ could be a single response beginning with that letter. Further, let $P(x ; R)$ denote the probability that $x$ is $271 / 3,639$ is the proportion of all chosen when the choice is explicitly responses given that are "violin," while restricted to members of the set $R$. For $271 / 422$ is the proportion of Ss who gave example, if $x=$ violin, and $R=$ all musical "violin" as a response. Similarly, the instruments beginning with the letter $\mathrm{V}$, response "viola" was given 59 times. $\mathrm{P}(\mathrm{x} ; \mathrm{R})$ would denote the probability of "Violin" and "viola" are the only musical "violin" as an associate to the cue "musical instruments starting with $\mathrm{V}$ that appeared instrument-V." Let $P(R ; C)$ be the in the norms. If we were to interpret $271 / T$ probability of choosing any element in the and 59/T as true probabilities in the sense set $\mathbf{R}$ when the choice is restricted to of Luce's axiom, one would expect that members of $C$ and let $P(x, C)$ be the the stimulus "musical instrument starting probability of choosing a particular $x$ from with V" would lead to the response C. Given this notation, then Luce's basic "violin" a proportion calculated according axiom states that:

$$
P(x ; C)=P(R ; C) \cdot P(x ; R) . \quad \text { (1) } P(\text { violin; instrument }-V)=\frac{271 / T}{271 / T+59 / T}
$$

An equivalent formulation is

$$
\begin{aligned}
& =271 / 330 \\
& =.82
\end{aligned}
$$$$
P(x ; R)=P(x ; C) / P(R ; C) .
$$ 
Fig. 1. Scatter diagram of observed vs predicted proportions.

Similarly, "viola" would be expected to occur as the restricted associate for the remaining .18 of the cases. In these expressions, the base $T$ cancels from numerator and denominator so that the fact that it varies across categories is immaterial.

For each restricted association task, the responses of our Ss provide an empirical estimate of the probability of any single response meeting the restrictions. For example, to "musical instrument starting with V," $85 \%$ of our Ss gave "violin" and $15 \%$ gave "viola." Corresponding to each restricted associate, we can also calculate a theoretical prediction from Luce's axiom using the Battig and Montague norms as illustrated above. The central question is how closely the predicted proportions approximate the empirical proportions.

\section{METHOD}

The Ss were 40 Stanford undergraduates who received $\$ 2.00$ for a 1 -h session.

Stimuli were printed on $5 \times 8$ in. cards, each containing a category plus either a restricting letter or a restricting adjective. Examples are: flower-P and bird-yellow. Each pair could be presented with a short $(1 / 2-\mathrm{sec})$ or a long ( 5 -sec) interval between the two elements and with either the category first or the category second. There were 384 unique items (96 pairs $\mathrm{x}$ 2 intervals $\times 2$ orders). Each $S$ received a random selection of 96 items, with the restrictions that each category appear twice, once with a letter and once with an adjective, and that for each set of four $\mathrm{Ss}$ each of the 384 items appear exactly once. A condition on the random trial sequence was that if $S$ received a pair such as flower-P, then at least 24 trials had to elapse before he received another pair including either flower or $\mathrm{P}$.

A trial consisted of the following: (1) A card with the item printed in large type was placed in a darkened enclosure behind a half-silvered mirror. (2) E said, "Ready," and pressed a button that illuminated the first number of the stimulus pair. (3) A short or long interval passed. (4) The second element of the restricting pair was illuminated and simultaneously an electric timer with a dc clutch was started. (5) S's verbal response activated a voice key that stopped the clock and terminated the trial. If the item was a category plus a letter, $S$ was told to respond with the first word he could think of begiıning with the letter given and bclonging to the category. If the item was a category plus an adjective, $S$ was to give an associate that belonged to

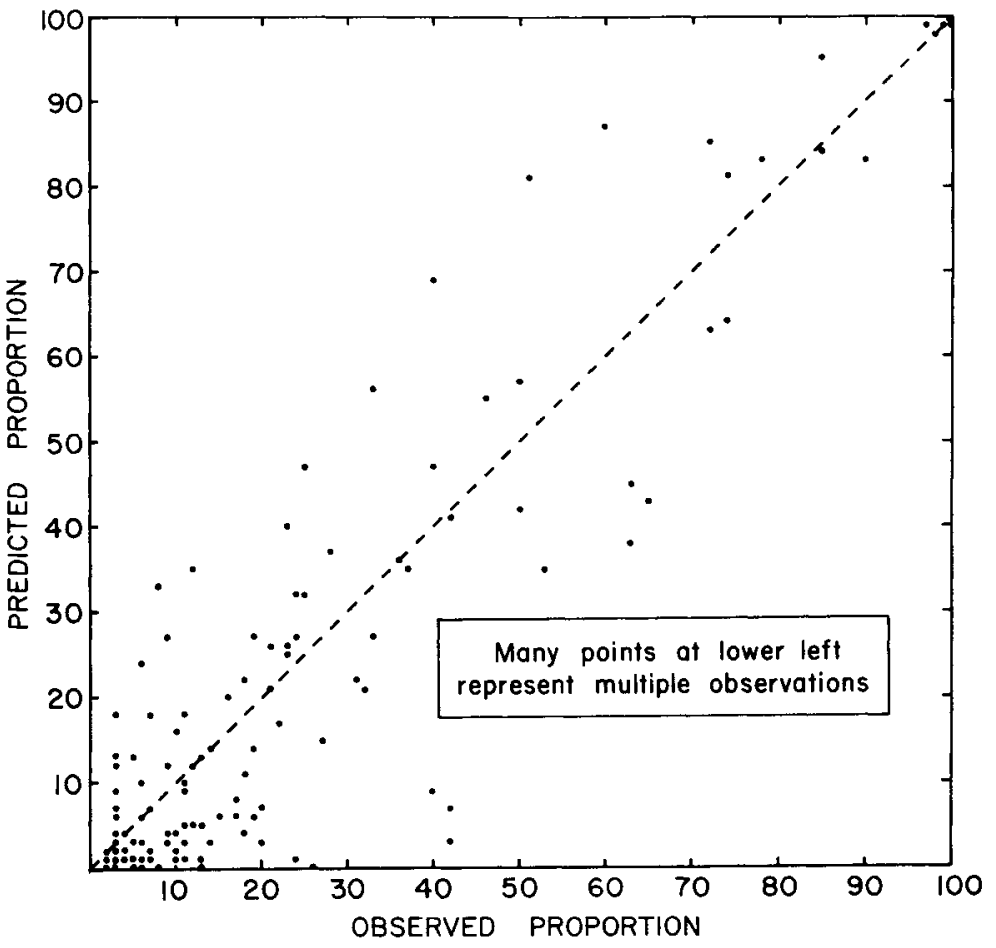

the category and to which the adjective was applicable. The $S$ was told to respond as quickly as possible, but was also urged to avoid errors. A warm-up period of 15 trials preceded the experimental trials.

\section{RESULTS AND DISCUSSION}

Only responses to the category-letter items and for categories represented in the Battig and Montague norms are used in the following analyses. There were 33 such categories for each of which we have responses from $40 \mathrm{Ss}$. There were a total of 155 responses that our Ss gave and that also appeared in the Battig and Montague norms. The number of different responses per restricted category varied from 1 to 14 , with a mean of 4.7 .

Predicted probabilities from Luce's axiom were calculated for the 155 responses. The empirical proportions are simply the percentage of Ss giving each response. Figure 1 is a scatter diagram of the observed vs predicted proportions. The observed and predicted proportions are strongly related (Pearson correlation $r=.91)$. It should be noted that there is a dense cluster of points at the low end of the scale representing infrequent responses that are predicted to be infrequent, and these contribute substantially to the correlation; but the agreement is clearly quite good throughout the range.

A few of the very discrepant predictions dramatically demonstrate some of the hazards of using norms collected on one sample to fit associations of a different sample of Ss. The Battig and Montague Ss were students at the University of Maryland and University of Illinois. As would be expected, they give quite different associates to "State" and "City" from those given by the Stanford Ss used here. Also, the normative data were collected over 4 years ago, and some of the verbal hierarchies have undergone change due to accretion and deletion. For example, to the cue "a type of dance beginning with B," $26 \%$ of our Ss said "bugaloo," which is currently popular but was not yet invented in 1965 , hence it does not appear as a response in the norms. Conversely, names of some dances popular in 1965 are very rare today. Nevertheless, removing such clearly deviant categories (20 points), raises the overall correlation only .02 (to .93). Thus, despite the slight inappropriateness of Luce's model to the norm collection procedure and the occasional misfit of norms between different subject pools, Luce's axiom predicts the contrained associate probabilities with considerable accuracy.

\section{REFERENCES}

BATTIG, W. F., \& MONTAGUE, W. E. Category norms for verbal items in 56 categories: A replication and extension of the Connecticut category norms. Journal of Experimental Social Psychology. Monograph, June 1969

LUCE, R. D. Individual choice behavior: $A$ theoretical analysis. New York: Wiley, 1959. NOTE

1. The authors are indebted to Dr. Gordon $\mathrm{H}$. Bower for his insightful comments and critical readings of this report. The study was supported in part by a grant from the National Science Foundation to J. Freedman. 